\title{
Research on Lifelong Education Based on Erikson's Psychosocial Development Theory
}

\author{
Xue Sun ${ }^{1, *}$, Ting Sun $^{2}$ \\ ${ }^{1}$ School of Public Finance and Administration, Harbin University of Commerce, Harbin, Heilongjiang 150028, China \\ ${ }^{2}$ School of Public Finance and Administration, Harbin University of Commerce, Harbin, Heilongjiang 150028, China \\ *Corresponding author. Email: 1481389882@qq.com
}

\begin{abstract}
Erikson's psychosocial development theory for the first time extends the formation and development of psychology to the whole life of human beings and divides the development of life into eight stages, so that people can not only look forward to the future but also look back on the past in the course of life development. It also sums up the core tasks and crises faced by people at each stage of development, which provides theoretical reference for education of different age groups, and has great guiding significance for family education, social education and even school education.
\end{abstract}

Keywords: Erikson's Psychosocial Development Theory, Education, Lifelong Education, Stages of Development.

\section{INTRODUCTION}

\subsection{Erikson's Psychosocial Development Theory}

Erikson's psychosocial development theory holds that a person should go through eight stages of psychosocial evolution, which is called psychosocial development. These stages include four childhood stages, one adolescence stage and three adulthood stages. These stages are closely linked, and each stage is based on the previous stage. The order of development is fixed. The stages of development are ubiquitous in different cultural environments and determined by genetic factors. Each stage has a corresponding core task, which determines the individual's psychological development. When the task is properly resolved, the individual will obtain a relatively complete identity. On the contrary, there will be a state of incomplete and incoherent personal identity [1].

\subsection{Theory of lifelong education}

Life-long education refers to the sum total of education received by people at various stages of their lives, which is the sum total of all kinds of education received by people. In other words, life-long education is not an educational system, but the principle on which the overall organization of a system is based, which in turn runs through the development of each part of the system.
The general view of life-long education is that life-long education is the sum of all kinds of training people have received in their lifetime. It means that it begins at the beginning of life and ends at the end of life, including all stages of human development and all aspects of educational activities. The various levels and types of education that a vertical person receives at different stages of development from infancy to old age, as well as the horizontal levels of education in different areas of school, family and society, its ultimate aim is to maintain and improve the quality of an individual's social life.

\section{STAGES OF DEVELOPMENT}

\subsection{Infancy (from Birth to 12 Months): Trust vs. Mistrust}

At this stage, if caregivers can meet a child's basic needs for survival, the baby will develop a sense of trust and see the world as safe, which is the most basic selfidentity awareness. Success in this stage will lead to the virtue of hope. The infant can have hope when facing setbacks and failures. Failing to acquire the virtue of hope will lead to a yellow-bellied personality [2]

\subsection{Toddlerhood (Aged 1.5-3 Years): Autonomy vs. Shame}

At this time, toddlers quickly learn and master basic 
skills, such as climbing, walking, and speaking, and begin to show clear personal preferences "with will". They will consider whether to stick to or give up, and this stage is also called the first period of resistance. At this stage, parents need to help the child develop a sense of autonomy, eliminate self-doubts and have a more independent personality.

\subsection{Preschool Period (Aged 3-6 Years): Initiative vs. Guilt}

After going through the first two stages of development, children have realized that they are human beings, and begin to initiate more motor activities, imitate the behavior of people around them, be able to use language more accurately, use imagination more vividly, actively explore within limits and have a try. If children's original behavior and imagination are allowed and encouraged at this stage, it will help them develop the virtue of purpose and ambition and prevent children from forming an inferiority personality.

\subsection{School Age (Aged 6-12 Years): Industry vs. Inferiority}

Different from the first three stages, children's education in this stage gradually changes from family education to school education, so this period is usually called elementary school stage. At this stage, if children are encouraged and reinforced for their initiative, they begin to feel industrious and feel confident in improving their ability to handle affairs independently. However, if they do not successfully accomplish the core tasks at this stage, children will become inferior and negative [3].

\subsection{Adolescence (Aged 12-18 Years): Identity vs. Role Confusion as}

In adolescence, children face the task of identity vs. role confusion. Some people also call this stage a rebellious period. Because self-identity is a series of feelings about "who I am? What position I should occupy in society? What do I want to do with my life? and How do I strive to be the person I want to be? The formation of self-identity is closely related to career choices, gender roles and the outlook on life. Erikson called this period the psychological moratorium, which is used to express the interval between youth and adulthood [4].

\subsection{Early Adulthood (Aged 18-25 Years): Intimacy vs. Isolation}

This period of development can be called early adulthood. At this stage, intimacy and isolation are a pair of major conflicts. At this stage, people need to cultivate the ability to interact with others. If the conflict at this stage can be successfully resolved, the virtue of love can be formed. If not, people may experience feelings of loneliness and emotional isolation and develop chaotic sexual relations [5].

\subsection{Middle Adulthood (Aged 25-50 Years): Generativity vs. Stagnation}

This period of development can be called middle adulthood. The social task at this stage is generativity vs. self-focus. At this stage, if identity is formed and life is happy, then the adults will want to pass on such environment to the next generation, which will make generativity dominate the above contradictions and thus cultivate the virtue of care. But if not, people will be selfish and only focus on themselves taking themselves as the center.

\subsection{Late Adulthood (after 50 Years Old): Ego Integrity vs. Despair}

This period of development is known as late adulthood. Erickson's task at this stage is called ego integrity vs. despair. At this stage, when reflecting on their lives, people who feel proud of their accomplishments feel a sense of integrity and no despair, thus obtaining the virtue of wisdom. But if not, people will face the end of their lives with feelings of disappointment and meaninglessness.

\section{ENLIGHTENMENT OF ERIKSON'S PSYCHOSOCIAL THEORY ON LIFELONG EDUCATION}

Erikson's theory not only emphasizes the psychological basis, but also emphasizes the physiological basis. It extends the stages of psychological development to the whole lifetime, and puts forward the core tasks and crises of each stage, so that people can not only look forward to the future but also look back on the past, providing a theoretical basis for educators in implementing the educational acts at each stage. It has great guiding significance for family education, social education and even school education.

\subsection{Education is a Process of Promoting People's all-round Development}

Education is a process of cultivating people's allround development. In infancy, children's virtue of hope and will should be cultivated, so that children are full of hope and courage for the future, and when doing things, they can also have the spirit of active endeavor. In early childhood, children need to be able to do things purposefully and in a planned way. In childhood, we should cultivate children's industrial and independent personality, so that children can develop the habit of studying and working hard. In adolescence, teachers need to cultivate children's virtue of loyalty, and their ability of sticking to identity, and train their ability to love and be 
loved. In adulthood, gradually growing mature at this time, people should cultivate the character of caring for the weak and daring to take responsibility. With these characters and abilities, people can achieve self-integrity in late adulthood.

\subsection{The Educational Principle Should be Step by Step}

Erikson's theory is characterized by gradual formation, which holds that the next psychological stage is the continuation of the previous psychological stage in time and space. Moreover, education itself is not an overnight act. Both subject education and moral education should be carried out step by step, follow and respect the law of individual growth, and carry out teaching in plans and stages [6]. For example, in infancy, attention should be paid to observing the interest of children and carrying out targeted development of interest. In early childhood, we should guide them and cultivate their spirit of actively seeking knowledge. In childhood, it is more important to cultivate their interest in learning than to learn more difficult knowledge. In adolescence, that is, in middle school, if teachers can communicate more closely with the children at this time, they can make children more susceptible to their influence and follow their instruction. In adulthood, a person has a sense of self-discipline and develops the ability and habit of independent learning, so that the person can learn the knowledge one needs without the guidance of teachers.

\subsection{The Role of Family Education Should be Stressed}

The importance of family education has gradually been affirmed by the society. From the infancy, family education has already started, and plays a foundation role in the process of life education and being educated. Children can develop their trust in the world when receiving care from parents, which is the necessary prerequisite for forming a healthy personality and the foundation of personality development at all stages. This requires parents to smartly integrate education with care for their children. First of all, we should establish a harmonious parent-child relationship, meet their basic needs in a timely manner, and create a peaceful and comfortable environment for children. At the same time, we should provide positive regard to children, give positive responses to children's behaviors, and let children see the world as safe, thus forming a stable attachment relationship between parents and children. Secondly, parents should be appropriate in education, not be excessively sharp, restrictive, punitive, critical or over-protective, and have rational enduring spirit, but they must still firmly ensure the development of children's behaviors within social limits.

\subsection{Pay More Attention to the Education of the Aged}

Life-long education is an educational concept, that is, the sum of a person's life education and the education of the individual and the whole of social life, emphasizing the provision of the necessary knowledge and skills in the best way at the time of each person's need. In late adulthood, however, people often neglect education by thinking they are getting old and focusing their lives on future generations. According to Sven-Göran Eriksson's theory of personality development, there is still a core task at this stage, so it is very important for the mental health of the elderly to set up the concept of life long education and life long learning so as to enrich their life in old age, moreover, the elderly have more leisure time, can develop their own hobbies, go to university for the elderly, participate in physical exercise, constantly enrich their lives [7].

\section{CONCLUSION AND SUGGESTION}

Erikson's psychosocial development theory is scientific and logical, which provides theoretical basis and content for education of different age groups. However, Erikson's point of view also has certain limitations. He overemphasizes the order of development stages, but does not emphasize the critical stages of overall development and the critical period of each development stage. As parents or teachers, in the process of educating the children, they should fully consider the differences in individual development and individual subjective initiative based on the reality, and better use Erikson's theory to solve practical educational problems.

\section{ACKNOWLEDGMENTS}

Thanks to the teachers for their guidance and learning and exchange opportunities provide by this meeting, it provides more academic exchange platforms for our students.

\section{REFERENCES}

[1] Feng Xue. Discussion on Erikson's Theory of Psychosocial Development[J]. Literature Education (volume II). 2020(02): 48-49.

[2] Wang Jiajun. Erickson's Theory of Personality Development and the Cultivation of Children's Healthy Personality [J]. Preschool Education Research,2011(06):37-40.

[3] Liu Qian, Wang Shuo, Li Yunpeng, Zeng Ting. The Predicament and Countermeasure of Sports Cultivation of Teenagers' Personality from the Perspective of Erikson's Theory[J]. Sichuan Sports Science. 2021, 40(01): 51-54. 
[4] Wang Xiaoyan, Zhou Xia. On the Dilemma about the "Self-development" of College Students from the Perspective of Psychosocial Development Theory[J]. Journal of Beijing University of Chemical Technology (Social Sciences Edition). 2020(02): 103-108.

[5] Gu Hang. Analysis of Adult Personality Development from the perspective of Erikson's Psychosocial Development Theory[J]. Writer's World. 2020(24): 192-193.
[6] Lei Yiming. Exploring the Educational Significance of the Principle of Gradual and Orderly Progress from the Perspective of Erikson's Psychosocial Development Theory[J]. Shanxi Youth. 2020(11): $259+261$.

[7] Zhang Jingjing. View of education based on SvenGöran Eriksson's view of personality development $[\mathrm{J}]$. Science, education and culture (first edition), 2017(11) : 27-28. 